\title{
Loan Recovery Monitoring Mechanism
}

\author{
Rakesh Sah
}

\begin{abstract}
This paper proposes the use of Macaulay Duration as an operational and objective measure of the performance of loan repayments. It uses the Macaulay Duration measure to calculate the Duration of an individual loan and shows how changes in calculated Duration vary over time with loan repayments, prepayments or defaults. These changes in Duration are used to provide an objective measure for the repayment performance of loans. The duration approach also allows the construction of a numerical measure for the loan repayment performance of a portfolio of loans that has unique characteristics, or for the overall loan repayment performance of a financial institution or a larger economic region. The model is ideally suited for Microcredit institutions that are scarce on resources to monitor their loan portfolios.
\end{abstract}

Index Terms-Duration, loan repayment, microloans.

\section{INTRODUCTION}

Loan Recovery is of utmost importance to all financial institutions (FI's). Pennacchi [1] proves that large FI's monitor their loans on an ongoing basis and this helps in reducing the cost of capital. Lee and Sharpe [2] also emphasize the importance of monitoring bank loans. However, for such large institutions loan recovery though important is not imperative, because loan portfolios of such institutions are usually backed by collateral of equivalent or greater value. In the case of Micro Financial Institutions (MFI's) timely loan recovery can be a question of survival. MFI's are usually supported by donors who might be governmental or privately funded organizations or both. Regardless of the source of funding for MFI's a common vein that runs through all such sources is that, funding is finite.

There are many measures of loan delinquency. However, most of these measures are either ratio based, [3], or they use complex econometric models, [4]. Theoretical models have been developed by [5]. These models are not very illuminating and not of much practical use. In the case of ratios, as [6] points out, "the result of dividing some numerator on the top of the fraction by some denominator.... Unless we know exactly what goes into the numerator and the denominator, delinquency ratios are more likely to obscure the real situation". Further, "the MFI has to settle for a less-than-ideal version of an indicator because its systems cannot produce the information needed for the ideal indicator it would have preferred" [6]. Econometric models on the other hand deal more with the determinants of loan recovery rather than with their measurement, [7]. Models like those

Manuscript received June 10, 2014; revised August 15, 2014.

Rakesh Sah is with the College of Business, Montana State University, Billings, MT 59101 USA (e-mail: rakesh.sah@ msubillings.edu). provided by [8], are also very cumbersome to use and require the presence of an in-house econometrician. Currently, there is no Econometric model that can be used to determine the repayment performance of an individual loan over its life, though [9] develop intensity models for a group of credit card loans.

We propose a model that uses Macaulay's Duration [10]. This model is dynamic, in not dependent on accounting practices, has memory, accounts for both late payments and prepayments, and can be aggregated from an individual to a group or institutional level. Weil [11] summarizes some of the development history and uses of Duration. The Macaulay's Duration model is uniquely suitable for MFI's because of its simplicity and ease of use, and it can also be used to make comparisons across lenders, branches, regions, and MFI's.

\section{LITERATURE REVIEW}

There is a paucity of literature on measuring the performance of loan repayments. The standard approach is to use traditional ratio analysis for this purpose. Rosenberg [6] succinctly sums up the various approaches and their shortcomings. Rosenberg [6] identifies five qualities of a good loan repayment measurement indicator: Red flag, Fire bell, Bottom line, Smoke and mirrors, and Cash flow. The Red flag is a first alarm: "does the delinquency ratio support timely response to day-to-day repayment issue." The Fire bell is a full blown alarm: "when delinquency has reached dangerous levels, does the ratio reveal the seriousness of the problem or does it tend to camouflage it." The Bottom line test "permits estimates of actual loan losses likely to result". The Smoke and Mirrors test doesn't encourage "inappropriate rescheduling or refinancing of loans, or manipulation of accounting policies" to project a favorable loan payment scenario and the Cash flow test "helps us predict the flow of cash from our portfolio, so that we can balance sources and uses of funds to avoid running out of cash."

Rosenberg [6] explores seven ratios, namely, On-time collection rate, Asian collection rate, Current collection rate with loan loss rate calculation, Cumulative collection rate with loan loss rate calculation, Arrears rate, Aged portfolio at risk with historical reserve schedule and the Simplified portfolio at risk. None of the ratios that he studies meets all the five qualities of a good indicator.

The On-time collection rate is calculated by dividing sums that have been paid in cash on time by the amount falling due for the first time. It does not include overdue payments. This ratio gives "instantaneous and unambiguous feedback about the timeliness of client payments." This approach does not meet the Bottom line and the Smoke and Mirrors test but is the best Red Flag performer.

The Asian collection rate is calculated by dividing all cash 
collected during a period by all cash that is due up to that point in time. It includes all amounts that are past due. This "money lenders" method does not meet any of the tests.

The Current collection rate is all cash received in payments of loans during the period while the denominator is all amounts that fall due for the first time during the period. This method does very well on the Bottom line test but lags on the Red Flag test.

The Cumulative collection rate is calculated by dividing all principal payments received, since the inception of the program, by all repayments of principal that have fallen due. This ratio, when accompanied by the loan loss rate, does well on the bottom line test.

The Arrears rate is calculated by dividing late payments by the outstanding portfolio of loans. It compares missed payments with the total outstanding portfolio and is not a good measure of loan repayment performance.

The Portfolio at Risk (PAR) is outstanding balance of loans with overdue payments divided by the total outstanding balance. The Aged PAR is obtained by dividing the portfolio into tranches depending on the degree of lateness. Therefore, loans that are between 1 to 7 days late could be one tranche, 8 to 14 days another, and so on. An aged PAR is the best performer among all the ratios and passes all except the Smoke and Mirrors test and the Cash Flow test.

The Simplified Portfolio at Risk is the percentage of active loan accounts that are overdue. This measure uses the number of accounts rather than a monetary number and is a risky measure because it treats an account with a very large outstanding balance, the same as an account with a small outstanding balance. It does not meet the Bottom Line Test and the Cash Flow test.

Rosenberg [6] is silent on the issue of partial loan repayments. For example if the borrower has to repay 400 Takas per month but is only able to repay 275 Takas, how would it be accounted for in a loan repayment analysis? This is more relevant in the case of microloans because a borrower who uses the loan for an income generating activity may be able to repay only a part of the repayment due, for extended periods of time. This could be due to the seasonal nature of the income generating activity or simply because of business risk. The Duration based measure is immune to the problem that arises from partial payments.

Ratio based measures also do not properly account for prepayments. What are the consequences of prepayment for a borrower and a lender? The borrower may have prepaid the loan to simply get rid of a future liability or because the cost of borrowing may be more than the return that the borrower can generate from using that loan. For the lender, however, there are some consequences. First, the lender has to forgo the return for the remaining period of the loan, especially if the lender cannot find another borrower or another investment opportunity. In either case there will be costs associated with either finding a new borrower and completing the necessary paperwork, or finding a new avenue for investment.

We propose the use of a measure based on Macaulay's Duration [10] formula. The Duration formula and its many modifications [11], are very popular in measuring changes in the value of a Bond Portfolio in response to changes in the rate of interest. Duration can also be used for hedging purposes in Forward and Futures markets. Another possible use of Duration is for Asset-Liability Management in Commercial Banks. In this paper we use Macaulay Duration to monitor the repayment performance of an individual loan, borrower, or category of loans. These can be aggregated to monitor the loan repayment performance of an officer [5], branch, division, enterprise or a geographical region or even an economy.

\section{RESEARCH METHOD}

Macaulay's Duration measure is very popular in financial literature and most undergraduate Finance textbooks, [12] cover the concept of Duration in some detail. In a modified form it is primarily used for portfolio hedging purposes, [11]. It can be also used in the Asset-Liability management of commercial banks, [13]. The most common use, however, is in controlling interest rate risk, [14]. Vuuren and Styger [15] propose a different duration measure and its applicability in interest rate risk management and asset liability management. In this paper, we will first demonstrate a simple version of the Duration measure, as expounded by [10], applicable to an individual loan and then make additions so that it can be used to construct a Loan Repayment Index for an individual borrower. Then we will expand this index to a group and then construct a composite index for the Financial Institution.

Let ' $A$ ' be the amount of loan received by a borrower at time $T=0$. This loan is to be amortized by making ' $M_{t}$ ' $(t=1$, $2,3 \ldots \ldots \ldots N)$ periodic payments over the life ' $N$ ' of the loan. The continuously compounded discount rate applicable to this loan is ' $R$ '. (The assumption of continuous compounding is not crucial to our method, we could have used discrete quarterly, semi-annual or annual compounding).

Macaulay's Duration [10] $D$, is a measure of the weighted average time taken to recover all future payments. It can be mathematically represented as:

$$
D=\left[\frac{1}{A}\right] \sum_{i=1}^{N} M_{i} T_{i} \operatorname{Exp}\left(-R T_{i}\right)
$$

where

$$
A=\sum_{i=1}^{N} M_{i} \operatorname{Exp}\left(-R T_{i}\right)
$$

The first step in constructing the index is calculating at $T=0$, the Expected Duration of the loan in each succeeding payment period assuming that the borrower makes all payments on the dates that the payments are due. That the borrower may not follow the ideal payment pattern is acceptable. Further, the denominator in the Duration calculation remains the amount of the loan $A$.

$$
D_{r}=\left[\frac{1}{A}\right] \sum_{i=r}^{N} M_{i} T_{i} \operatorname{Exp}\left(-R T_{i}\right) ; 0<r<N
$$

Let the value of these Expected Duration be $E\left[D_{k}\right], k=1,2$, $3 \ldots \ldots \ldots . . N$; such that $E\left[D_{1}\right]$ would be the duration when only one month is left until the date of last payment, $E\left[D_{2}\right]$ would be the duration of the loan when two months are left on the loan, and so on. $E\left[D_{k-1}\right]$ would be the duration after one month 
of granting the loan and $E\left[D_{k=N}\right]$ is the Duration on the date the loan is made and will be equal to the value given in equation (1).

Over the course of the loan Duration is calculated on each date or end of each period that a payment is due to the lender. Let the value of the Actual Duration be given by $A\left[D_{s}\right] ; s=1$, $2,3 \ldots \ldots \ldots . N$. Now, over the course of the loan the borrower may make all payments on time, make some late payments but ultimately repay the loan, or make some payments and then default on the loan. The borrower could also choose to make no payments and default on the loan. In many cases, the borrower could choose to prepay the loan. Regardless of the scenario that ultimately plays out the index will be able to capture the repayment behavior of the borrower. Let us deal with each scenario.

\section{A. Case 1: The Ideal Borrower}

The ideal borrower makes all payments on the due date and the amount of each payment made is equal to the amount that was due. There is no prepayment on the loan. In such a scenario the Expected Duration of the loan and the Actual Duration of the loan will be equal on each repayment date.

$E\left[D_{k}\right]=A\left[D_{s}\right]$; for all $k=s$, and the Duration ratio will equal unity, i.e. The Duration ratio $=\left\{A[D s] / E\left[D_{k}\right]\right\}=1$.

\section{B. Case 2: The Forgetful Borrower}

As long as a borrower makes payments on time the Duration ratio of the Actual to the Expected Duration will always equal unity. But suppose a borrower makes $(p-1)$ : $[2<p<N]$ payments on time but for some reason does not make the $p^{\text {th }}$ payment on the date it is due. This future value of this payment that was due at time $\mathrm{p}$ will now be added on to the amount of the last payment at time $N$. This addition of future value to the last payment will make the Actual Duration of the loan greater than the Expected Duration. Therefore, the value of the Duration ratio will be greater than unity, i.e. The Duration ratio $=\left\{A\left[D_{s}\right] / E\left[D_{k}\right]\right\}>1$.

In a limiting case where the borrower makes no payments and the entire loan is overdue the duration ratio will tend to infinity.

\section{Case 3: The Eager Borrower}

Oftentimes borrowers make a prepayment into a loan account. They might choose to make an entire payment amount before the due date or may choose to make a partial future payment. In such cases calculate the future value of the overpayment at the next due date and subtract it from the next payment that is due. Let overpayment at time $\mathrm{r}$ be denoted by $O_{r}$ : where $O_{r}=\mathrm{PM}_{r}-\mathrm{PD}_{r}$; and $\mathrm{PM}_{r}$ is the actual payment made at time $\mathrm{r}$ and $\mathrm{PD}_{\mathrm{r}}$ is the cash payment due at time $\mathrm{r}$. Further, let $S_{r+1}=\mathrm{FV}_{r+1}\left[O_{r}\right]$, where $\mathrm{FV}_{r+1}\left[O_{r}\right]$ is the future value at time $(\mathrm{r}+1)$ of the overpayment that was made at time $r$. Subtract $S_{r+1}$ from the payment due at time $r+1$. This is the Cash flow, $M_{r+1}\left[=\left(\mathrm{PD}_{r+1}-S_{r+1}\right)\right]$ to be used at time $r+1$ for calculating the Actual Duration at time $r, A\left[D_{r}\right]$.

$$
\begin{gathered}
A\left[D_{r}\right]=\left[\frac{1}{A}\right] M_{r+1}(r+1) \operatorname{Exp}\left(-R T_{r+1}\right) \\
+\left[\frac{1}{A}\right] \sum_{i=r+2}^{N} M_{i} T_{i} \operatorname{Exp}\left(-R T_{i}\right)
\end{gathered}
$$

The Duration ratio $=\left\{A\left[D_{s}\right] / E\left[D_{k}\right]\right\}<1$
If the borrower makes a prepayment on a loan or makes a partial prepayment on the loan the Duration ratio will be less than unity.

In a limiting case when the actual duration is zero, i.e. when the borrower has prepaid the entire loan amount, the Duration ratio will be 0 .

\section{RESULTS}

The value of the Duration ratio changes as the borrower makes or does not make payments. In the case of an ideal borrower, on who makes the exact payment on the exact due date, will always equal one. The Duration ratio will be less than unity for a borrower who prepays a loan and will always be greater than unity for a borrower who makes a late payment. Thus, any loan account will, during its life, have a series of duration ratio's that will tell the story of how timely the borrower repaid the loan. For example, a loan has Duration ratios of $1,1,1,1.2,1.7,1.5,1.3,1.1$, and the loan is paid off. This pattern indicates that the borrower made the first three payments on time, but defaulted on the fourth and fifth payments and then started making regular payments because the duration ratio starts decreasing after the fifth payment. Notice that the Duration will not be unity even after the borrower started making regular payments having once made a late payment. This is because the Duration ratio has memory of the late payment.

If a loan account has Duration ratios of $1,1,0.8,0.9,1.4$, $1.2,1.1$, and the loan is paid off. This indicates that the borrower made the first two payments on time prepaid the third payment (or part of it), prepaid a part of the fourth payment, and then made a late fourth payment. From the fifth payment onwards, the borrower seems to be making regular payments as the Duration ratio starts decreasing.

\section{A. Portfolio Duration}

The concept can be extended to a portfolio comprising a category (say all those over age 40). We first calculate the Expected Duration for each borrower at each payment date over the life of the loan. Note, that this does not require that the payment dates be identical or that the loans be coterminous. At each date we can calculate the Expected Duration of the category portfolio $E[D P]$ using a weight average with the weights being proportional to the expected amount of loan outstanding.

$$
E[D P]=\sum_{v=1}^{Q} w_{v} \times A\left[D_{v}\right] ; v=1,2 \ldots . Q
$$

$Q$ is the total number of loans outstanding for that category and $w_{v}$ is the weight assigned to the portfolio:

$$
w_{v}=L_{v} / \sum_{v=1}^{Q} L_{v} ; v=1,2 \ldots . Q
$$

$L_{v}$ is the expected value of the amount of loan outstanding for the $v^{\text {th }}$ loan.

We can using the formula (6) and (7) calculate the Expected Duration of the portfolio over the life of the portfolio. Similarly, using the Actual Duration of the loans outstanding and the actual values of the amounts of loan outstanding we can calculate the Actual Duration of the portfolio. 


$$
w_{v}^{a}=L_{v}^{a} / \sum_{v=1}^{Q} L_{v}^{a} ; v=1,2, \ldots \ldots
$$

$L_{v}^{a}$ is the actual value of the loan outstanding for the $v^{\text {th }}$ loan.

$$
A[D P]=\sum_{v=1}^{Q} w_{v} \times A\left[D_{v}\right] ; v=1,2 \ldots \ldots . Q
$$

$A[D P]$ being the actual Duration of the portfolio.

The Duration ratio for the category portfolio $=A[D P]_{k}$ $/ E[D P]_{s}$ for all $k=s$.

The category Duration ratios can be read in the same manner as individual loans, with a value of 1 indicating that all the loans are being paid in a timely manner, a value less than 1 indicating loan prepayments and a value greater than 1 indicating that payments are not being timely. A high value of the category Duration ratios indicates problems for that category of loans.

An Enterprise Duration ratio can be obtained by using a weighted average of the category durations. First we calculate the expected value of the Duration $E[D E]$ for the entire Financial Institution at any point in time.

$$
E[D E] \sum_{g=1}^{Y} w_{g} \times A\left[D_{g}\right] ; g=1,2, \quad Y ;
$$

$Y$ is the total number of categories and $w_{g}$ is the weight assigned to the category.

$$
w_{g}=L_{g} / \sum_{g=1}^{Y} L_{g} ; g=1,2 \ldots \ldots . . Y
$$

Where $L_{g}$ is the expected value of the total loans outstanding for the $g^{\text {th }}$ category.

Next, we calculate value of the actual Enterprise Duration over the payment periods.

$$
w_{g}^{a}=L_{g}^{G} / \sum_{g=1}^{Y} L_{g}^{a} ; g=1,2 \ldots \ldots . . Y
$$

$L_{g}^{a}$ is the actual value of the loans outstanding for the $g^{\text {th }}$ category.

$$
A[D E]=\sum_{g=1}^{Y} w_{g} \times A\left[D_{g}\right] ; g=1,2 \ldots \ldots . . Y
$$

$A[D E]$ being the actual Duration of the Enterprise.

We can calculate the Duration ratio for the Enterprise: Enterprise Duration Ratio $=E[D E]_{k} / A[D E]_{s}$ for all $k=s$.

The Enterprise Duration Ratio can be interpreted in the same manner as the Category Duration Ratios and the Individual Loan Duration Ratios. The Executive management of a Financial Institution can set limits for Rosenberg's 'Red Flag' and 'Fire Bell' that best helps it in achieving its mission and goals. These limits will be expected to be different for each Financial Institution.

The Duration Ratio meets the bottom line test. The Duration Ratio indicates a borrower late payment on a loan. It also indicates if the borrower continues to default or whether late payments are made up at a later date. If a borrower totally defaults on a loan the Duration Ratio would tend to infinity because the value of Actual Duration ratio would be infinite, and Expected Duration would be 0 after the expected last payment date. Therefore, if there is no scope of recovery such loans would have to be written off. Also, an increasing
Duration Ratio would also indicate a loan heading towards default that may need to ultimately be written off.

The primary determinants of the Duration Ratio are Expected Duration, calculated when a loan is first made, and the Actual Duration which in turn depends on the amount of actual payment and the time of payment. These are insulated from accounting manipulation. Further, each individual loan account or borrower would have a track record, so renegotiated or rescheduled loans would be reflected in the Duration Ratio. A loan account for which payments are late would have a duration ratio greater than 1 , once the loan is renegotiated or rescheduled the duration ratio would again be unity on the renegotiated date. This is not possible for a loan that has had a late payment. Therefore, the Duration ratio performs well on the Smoke and Mirrors test.

The Duration Ratio calculations also provides an indicator of the cash flow. If borrowers make the required payments on time, the Duration Ratio will equal one and expected cash flows will equal actual cash flows. However, if the borrower is late in making a payment then the expression

$$
A=\sum_{i=1}^{Z} M_{i}^{Z} \operatorname{Exp}\left(-R T_{i}\right) ; z=1,2 \ldots(N-1) ;
$$

where $M_{i}^{Z}=$ value of payment due at time $i$

If the borrower is not current on the loan then the value in equation (14) will be greater than the value of the loan. If the borrower is current on payments then the value will equal the amount of the loan and if the borrower has made some advance payments then the value will be less than the amount of the original loan. An aggregate of all loans for a category will give an indication of the deviation of the actual cash flow from the desired cash flows. An aggregate across all the categories will give an indication of the deviation between the desired and actual cash flows.

The Duration Ratio method, in addition to meeting Rosenberg's five tests of a good loan repayment measure also has the advantage that it is easy to implement and a simple computer program can be written so that the user at the unit level, the branch level and firm level can easily monitor all loans and take follow up action. McNulty and Akhigbe [16] find a link between loan officer compensation and bank performance. Another added advantage of the Duration ratio method is that it can be used to monitor the performance of individual lending officials over time, including those involved in the recovery of loans.

\section{CONCLUSIONS}

The Duration Ratio method is a powerful and practical method in measuring the repayment performance. In addition to meeting Rosenberg's five tests it has other advantages as well. The Duration Ratio is not dependent on accounting principles, it is easy to use and needs only the payment dates, the expected payments, the actual payment and the interest rate on the loan. These variables are extremely difficult to manipulate or fudge. The Duration Ratio has memory of payments that were made late and it also accounts for partial payments and payments made in advance. It is able to retain a payment history of a borrower over time with reference to a 
number that is easy to understand. Further, it can be aggregated across many categories of borrowers and also an individual borrower who maintains multiple loan accounts at a single Financial Institution. At the Governmental level the Duration ratio can be aggregated for a single category across multiple lending institutions. The Duration Ratio method does not require elaborate computer paraphernalia and is easy and very inexpensive to implement across an enterprise.

\section{REFERENCES}

[1] G. G. Pennacchi, "Loan sales and the cost of bank capital," Journal of Finance, vol. 10, no. 2, pp. 375-396, 1988

[2] K. Lee and I. G. Sharpe, "Does a bank's loan screening and monitoring matter?" Journal of Financial Services Research, vol. 35, no. 1, pp. $33-52,2009$

[3] A. Reichert and R. Posey, "Using financial ratios and lender relationship theory to assess farm creditworthiness," Accounting and Taxation, vol. 3, no. 1, pp. 45-56, 2011.

[4] H. Chou, "Using the autoregressive conditional duration model to analyse the process of default contagion," Applied Financial Economics, vol. 22, no. 13, pp. 1111-1120, 2012.

[5] T. L. Gollinger and J. B. Morgan, "Calculation of an efficient frontier for a commercial loan portfolio," Journal of Portfolio Management, vol. 19, no. 2, pp. 39-46, 1993.

[6] R. Rosenberg, "Measuring microcredit delinquency ratios can be harmful to your health," Occasional Paper No. 3, World Bank, Washington DC, June 1999.

[7] H. D. Khieu, D. J. Mullineaux, and H. Yi, "The determinants of bank recovery loan rates," Journal of Banking and Finance, vol. 36, no. 4, pp. 923-933, 2012
[8] R. Calabrese, "Predicting bank loan recovery rates with a mixed continuous-discrete model," Applied Stochastic Models in Business and Industry, vol. 30, no. 2, pp. 99-114, 2014.

[9] M. Leow and J. Crook, "Intensity models and transition probabilities for credit card loan delinquencies," European Journal of Operational Research, vol. 236, pp. 685-694, 2014

[10] F. R. Macaulay, "Some theoretical problems Suggested by the movement of interest rates, bond yields and stock prices in the US since 1856," National Bureau of Economic Research, New York, London Macmillan, p. 591, 1938.

[11] R. L. Weil, "Macaulay's duration: An appreciation," Journal of Business, vol. 46, no. 4, pp. 589-592, 1973.

[12] J. C. Hull, Futures and Options Markets, $7^{\text {th }}$ ed. Prentice Hall Publishers, 2011, ch. 6, pp. 142-146.

[13] M. L. Leibowitz, "Total portfolio duration: A new perspective on asset allocation," Financial Analysts Journal, vol. 51, no. 1, p. 139, 1995.

[14] N. F. Richie, R. Mautz, and W. H. Sackley, "Duration and convexity for assessing interest rate risk," Bank Accounting and Finance, vol. 23, no. 2, pp. 25-30, 2010

[15] G. van Vuuren and P. Styger, "Duration analysis in South Africa: The search for superior measures," South African Journal of Economics, vol. 74, no. 2, pp. 266-293, 2006.

[16] J. E. McNulty and A. Akhigbe, "Loan officer compensation and bank performance," RMA Journal, vol. 95 no. 9, pp. 12-14, 2013.

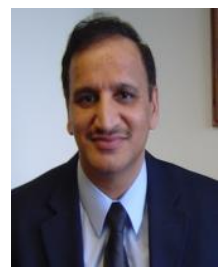

Rakesh Sah earned a Ph.D. degree in finance from University of Alabama, Tuscaloosa, AL, USA in 2000 He was also awarded a M.A. degree in economics from Lucknow University, UP, India in 1988.

$\mathrm{He}$ is currently a professor of finance at the College of Business, Montana State University Billings, Montana USA. His teaching and research interests are in applied finance and economics. Dr. Sah has extensive experience in rural and commercial banking. 